\title{
A AGÊNCIA DE GELL NA ANTROPOLOGIA DA ARTE
}

\author{
Caleb Faria Alves \\ Universidade Federal do Rio Grande do Sul - Brasil
}

\begin{abstract}
Resumo: Ao delinear os parâmetros para uma antropologia da arte, o famigerado livro de Alfred Gell, Art and Agency, deixou de lado boa parte da antropologia, o que coloca algumas questões tão embaraçosas quanto pouco tratadas: pode-se fazer boa teoria sem contar com o acúmulo de conhecimento nessa área? Ou os temas recebem tratamento tão díspar que realmente não faz sentido falar mais em princípios teóricos comuns que podem e devem ser aplicados a qualquer objeto? O que perdemos com uma narrativa tão autocentrada? Partindo do pressuposto de que não é possível tratar teoria enquanto um conjunto de máximas que se somam ou se substituem, ou como um tabuleiro de peças que se acomodam umas às outras segundo sua validade isolada, este artigo procede a um exame da narrativa contida no livro de Gell, das articulações que realiza entre suas proposições. Examinarei, sobretudo, a leitura que faz dos autores que cita, como Peirce, Sally Price, e outros, e como os encaixa na sua argumentação. O objetivo desse exercício é evidenciar, para além de suas próprias definições, certas concepções sobre arte contidas na abordagem que Gell sugere e ampliar as referências para uma antropologia da arte.
\end{abstract}

Palavras-chave: Alfred Gell, antropologia da arte, convenções simbólicas, teoria antropológica.

Abstract: While delineating the parameters for anthropology of art, the famous Alfred
Gell's book, Art and Agency, left apart most of the anthropology authors, what arises
some embarrassing and rarely dealt with questions: is it possible to produce good
theory with no references to achieved knowledge in this particular field? The subjects
within anthropology are so differently undertaken that doesn't make any sense to
refer to common ways of approaching them? What exactly we loose which a narrative
so self centered? Is my point of view that theory cannot be treated like a list of
sentences that can be added to one another according to its isolated importance. This
article proposes an analysis of Alfred Gell's narrative, of how he connects its
propositions. I will examine, overall, his readings, the authors he quotes, like Peirce,
Sally Price and others, and how he fits them on his argumentation. The objective of
this exercise is to put in evidence some conceptions about art contained in his

Horizontes Antropológicos, Porto Alegre, ano 14, n. 29, p. 315-338, jan./jun. 2008 
formulations, not only in his own definitions, and to enlarge the range within which we consider references to build anthropology of art.

Keywords: Alfred Gell, anthropological theory, anthropology of art, symbolic conventions.

Obras de arte são equivalentes a pessoas e a arte é um sistema de ação. É a partir dessas proposições que Alfred Gell (1998) define o que entende por uma antropologia da arte. Tais idéias, centrais ao seu pensamento, não soam tão esdrúxulas ao antropólogo. Ele está claramente evocando sistemas de pensamento diversos do nosso e nos conclamando a, ao invés de denunciar o artefato forjado da matéria inerte, assumir, a fim de entender, a assunção de que esses objetos são seres reais (já não mais objetos, portanto). Gell não pretende, entretanto, limitar-se a uma teoria da arte indígena. Estende, com audácia, suas concepções à produção artística ocidental. Colocado assim cruamente, é tentador assumir seu ponto de vista, pois parece calcado em modernas teorias acerca do respeito a diferentes lógicas de pensamento (cujo entendimento é, segundo ele mesmo, uma das tarefas da antropologia), além de incorporar a agência, termo caro à antropologia contemporânea. Considerando o impacto de seu livro gostaria de retraçar criticamente seus argumentos num exercício parco de reconstrução metodológica ${ }^{1}$ e ponderar sobre os parâmetros para uma antropologia da arte.

Gell praticamente não cita muitos dos grandes autores da antropologia, e, evidentemente, uma obra que passa ao largo da história da área na qual se insere contém inconsistências, ou nossos grandes mestres não têm nada a nos ensinar seja em termos específicos de uma antropologia da arte, seja no que diz

\footnotetext{
${ }^{1}$ Por reconstrução metodológica estou adotando o sentido exposto por Mario A. Eufrásio (1999, p. 251): "Numa primeira aproximação, poder-se-ia caracterizar a análise metodológica como o processo de identificação dos elementos constituintes dos discursos científicos (termos, enunciados, argumentos e formulações) quanto à sua estrutura, funções e relações em vários níveis e aspectos - ou, em outras palavras, o estabelecimento de modos de ocorrência e de relações entre esses elementos, estrutural e dinamicamente, em sua hierarquia, suas articulações, suas funções e validade 'finais' - e sua interpretação e avaliação metateóricas objetivas.” A rigor, não estou procedendo à reconstrução metodológica do livro de Gell, mas incorporo a atenção que esse exercício propõe ao conteúdo implicado na associação entre os elementos constituintes do discurso científico.
} 
respeito à aplicação à arte de princípios gerais do conhecimento antropológico. Essas lacunas não podem ser simplesmente somadas ou acrescentadas ao que Gell escreveu, nem o pensamento se constrói dessa forma cumulativa. Essas ausências, como espero demonstrar, sacrificaram em parte a consistência do que ele mesmo propõe, mesmo porque muitas idéias ali presentes já foram trabalhadas com profundidade por diversos autores, como, por exemplo, a própria noção de agência. O meu objetivo neste artigo, portanto, não é fazer um balanço da obra ou do autor, mas evidenciar o conteúdo implícito em certas associações entre proposições, em certas articulações de idéias, e depreender delas, com mais precisão, o modo como Gell entende a arte e o que está a ela relacionado, sobretudo em nossa sociedade.

Nesse sentido, não pretendo resolver problemas candentes da antropologia da arte nem ater-me às qualidades desse livro, já bastante expostas, mas ampliar os horizontes dentro dos quais eles são considerados. No geral, a impressão que tive, logo na primeira leitura desse livro, não é diferente daquela expressa no artigo crítico de Robert Layton (2003): ao mesmo tempo que revela problemas graves ao negligenciar o valor que a aproximação semiótica pode ter (desde que tomadas as devidas restrições ao modelo lingüístico) é brilhante. Assim, suas proposições ligadas à construção de uma antropologia que estude o funcionamento da arte no contexto onde é produzida (e eu acrescentaria como primeiro senão ao seu trabalho: e usufruída²), bem como de uma antropologia que seja aplicável a qualquer sociedade, são o ponto de partida desse artigo. O termo "estética", bastante revelador sobre seu entendimento da arte e do modo como constrói diferenças entre áreas do conhecimento, portanto da especificidade da antropologia, receberá destaque. ${ }^{3}$

O livro, como foi mencionado, não pontua amplamente a bibliografia antropológica sobre arte, no entanto, logo no segundo parágrafo ele cita uma produção recente de uma autora importante, mas que não é exatamente uma

\footnotetext{
${ }^{2}$ A fruição da obra de arte não depende dela ter sido produzida no meio onde é apreciada. Não há nada de artificial ou ilegítimo na incorporação de produtos externos ao grupo. Veja-se, por exemplo, o instigante trabalho de Cristina Torn (1988) sobre a apropriação de imagens da Santa Ceia entre os fijianos.

3 A atenção ao modo como Gell constrói seus argumentos não implica uma varredura total do seu livro, mas um olhar mais microscópico, que seja, porém, exemplar do todo. O meu foco será colocado nas primeiras páginas, onde ele expõe o principal da sua tese, com desdobramentos e exemplos tirados de diversos outros capítulos.
}

Horizontes Antropológicos, Porto Alegre, ano 14, n. 29, p. 315-338, jan./jun. 2008 
referência consagrada como Geertz ou Lévi-Strauss, trata-se de Arte Primitiva em Centros Civilizados, de Sally Price. Não são expostos os motivos para essa escolha, tais como a repercussão dessa obra ou outras que tais, de qualquer jeito, estamos diante do cerne a partir do qual Gell quer se posicionar: ele parte bem rapidamente para uma recusa desse trabalho enquanto um exemplo de antropologia da arte. A razão apresentada advoga que

Anthropology, from my point of view, is a social science discipline, no a humanity. The distinction is, I admit, elusive, but it does imply that the ' anthropology of art' focuses on the social context of art production, circulation, and reception, rather than the evaluation of particular works of art, which, to my mind, is the function of the critic. (Gell, 1998, p. 3).

Supondo que a presença de Price tenha uma função retórica, Gell quer distanciar-se de duas proposições contidas no trecho por ele citado: a primeira, de que o olho do connoisseur não é isento, ${ }^{4}$ e, segundo que, do mesmo modo, o olhar primitivo também tem seus discernimentos característicos. ${ }^{5} \mathrm{O}$ primeiro ponto de Price nos alerta para o etnocentrismo, para o quanto o julgamento do conhecedor de obras de arte é culturalmente orientado; o segundo para o fato de que o olho também é socialmente “educado”, ele vê o que é treinado para ver. Gell não discorda de nenhuma dessas afirmações, mas não as entende como definidoras de uma antropologia da arte. Ele imputa ao projeto contido nessas asserções o de elucidação de sistemas estéticos não ocidentais. Na imediata seqüência da citação de Price ele comenta o trabalho de Michaell Baxandall como alinhado a essa perspectiva, por ter demonstrado o modo de ver presente no Renascimento italiano. Gell assume momentaneamente essa posição apenas para destacar uma ressalva: se isso é verdade, entre a antropologia e a história haveria apenas a distinção de quais sistemas ambas as disciplinas elucidariam. A sua discordância contém um primeiro equívoco, sutil, mas importante, que introduz uma série de imprecisões que comprometem a abrangência de suas propostas, qual seja: a seqüência de argumentos apre-

4 “[...] the eye of even the most naturally gifted connoisseur is not naked, but views art through the lense of a Western cultural education.” (Price apud Gell, 1998, p. 2).

5 “[...] Primitives (including both artists and critics) are also endowed with discriminating eye [...]" (Price apud Gell, 1998, p. 2). 
sentada faz parecer que sistema estético e modo de ver presente em um sistema cultural são a mesma coisa.

Vemos, logo nessas primeiras passagens, que, sem dúvida, há uma atualização importante da abordagem da antropologia à arte, mas que também está ali presente o prenúncio de imprecisões conceituais, indistinções entre níveis de análise e exemplos um pouco tendenciosos, que correm o risco de repor práticas e formas de pensamento conservadoras que, ao cabo, comprometem a construção de uma teoria antropológica nos moldes como ele mesmo propõe. Isso fica mais evidente se olhamos um pouco mais em câmara lenta essas primeiras páginas e os elementos que ele mobilizou para cimentar essa distinção principal entre Sally Price e ele mesmo, entre "elucidar modos de ver" e uma antropologia voltada para relações sociais. A frase que abre o livro Art and Agency afirma que por uma teoria antropológica das artes visuais normalmente se entende uma teoria da produção artística em sociedades coloniais e pós-coloniais tipicamente estudadas por antropólogos, além de uma teoria sobre a chamada "arte primitiva”, agora denominada "arte etnográfica”, em coleções de museus. Uma teoria antropológica da arte seria uma teoria da arte voltada à arte antropológica. Em desafio a essas noções ele tece suas primeiras idéias: a de que uma teoria antropológica da arte não pode distinguir a arte produzida em nossa sociedade e em outras. Na seqüência ele introduz Price, já mencionada, passa por Baxandall e culmina com a sua proposição centrada em relações sociais, citada acima.

A crítica indireta a Baxandall é significativa porque esse autor é citado por Geertz (2000) em seu famoso ensaio Arte como Sistema Cultural como um excelente exemplo de como se faz uma etnografia da obra de arte, bem como por uma grande quantidade de antropólogos. Mais recentemente, o mesmo veio intelectual que deu origem ao trabalho de Baxandall inspirou os textos de Carlo Severi, numa série de textos renovadores da antropologia da arte, da imagem e da memória. No entanto, contrariamente ao que Gell escreveu, para esse historiador "um modo de ver" não equivale a um sistema estético. $\mathrm{Na}$ verdade, ele escreveu seu livro contra essa associação. A primeira frase de $O$ Olhar Renascente versa: "Uma pintura do século XV é o testemunho de uma relação social.” (Baxandall, 1991, p. 11). O seu interesse central são, portanto, relações sociais. A distinção é fundamental por uma razão muito simples, entender "um modo de ver" não serve para avaliarmos qualquer obra de arte que seja. Descortinar a “educação visual” de uma época não nos habilita e julgar ou pressupor julgamentos quanto a ser uma obra bonita ou não (supondo que o 
critério "beleza" seja importante). Nos torna capazes de entender o que foi mobilizado durante a apreciação e suas manifestações. Analisar juízos é um outro passo de pesquisa que pode ou não ser seguido conforme os objetivos do texto ou autor. Baxandall nos mostra o que provavelmente foi visto, não se quem viu gostou ou não, se achou tecnicamente bem executado, se uma determinada opinião tinha qualquer relevância ou mesmo se mobilizou algum parâmetro estético qualquer para emitir sua opinião.

Além disso, apesar da ligação que Gell estabelece entre Price e Baxandall, presente na seqüência de citações, o livro da primeira não contém investidas sólidas no sentido de entender modos de ver, senão de forma negativa, isto é, ela mostra o quanto o modo como vemos a arte primitiva está carregado de preconceitos. Sua pesquisa com críticos de arte, por sua vez, também não segue por essa via, poderia até ser classificada dentro de uma antropologia das profissões: discorre sobre suas identidades e suas compreensões a respeito do trabalho que realizam. Assim, o que Price pretende, diferentemente do que nos apresenta Gell, não é discutir o valor das obras de arte, indígenas ou não; ela discorre sobre a aplicação desse juízo, o que é bem diferente porque sua ênfase recai sobre classes de objetos. Suas conclusões dizem respeito, portanto, ao que se pode dizer sobre nossa sociedade a partir das pré-noções que temos sobre o outro descortinadas pelo modo como selecionamos a aplicação de critérios de julgamento estético. O ponto central é a seleção, não o julgamento. Ela nem chega a investigar se, e de que forma, esses valores repercutem fora desse grupo, o que seria bastante interessante.

Embora discorde da leitura que Gell faz de Price e de Baxandall, a crítica à primeira não é totalmente infundada. A ausência de análise de relações sociais é evidente e, nesse quesito, seu texto contém certas fragilidades. Essa lacuna é clara quanto ela parte para uma coleta de opiniões sem nos situar a que elas se referem. Por exemplo, sua entrevista com o guarda do museu, nos diz algo sobre o quê? Sobre o senso comum britânico? Sobre alguém formado em cursos específicos para atuar ali? Sobre a polícia? Sobre as convicções religiosas? Mas mesmo sendo mal embasada, a proposição geral de Price, de que os museus e suas coleções, mormente as de arte primitiva, dizem mais sobre nós mesmos do que sobre povos “primitivos”, é rica e muito instigante, e próxima ao que Gell propõe.

O que importa realmente, nesse momento, são as conseqüências que a leitura muito particular de Gell tem desses e de outros autores para o conjunto dos seus argumentos: a maneira como ele se expressa faz parecer que o deslindar 
do funcionamento de um grupo social é o mesmo que assumir seus valores. A estética pode perfeitamente ser objeto de análise antropológica, sem que por isso estejamos dentro da área da estética. A questão que isso nos coloca é até que ponto ele não reproduz o que condena, ou seja, um discurso, em última instância, ausente de relações sociais, pelo menos nos moldes propostos por Marcel Mauss. Contrariamente ao pensamento desse que ele diz ser sua inspiração para a construção de uma teoria antropológica, ele não incorpora a definição de arte presente em Etnologia e Antropologia, um dos principais guias para o trabalho do antropólogo. Nessa obra Mauss (1993, p. 9) propõe que arte é aquilo que é socialmente reconhecido como arte. ${ }^{6}$ Não há nada de tautológico na definição, como pode parecer à primeira vista. Mauss está preocupado com a institucionalização de algo como sendo o que é, com sua inserção na categoria na qual se encontra. Em outras palavras, com a absorção de um objeto dentro de um sistema classificatório que pode ou não ser o mesmo do pesquisador. Mauss quer evitar, com essa orientação, as pré-noções do pesquisador sobre o objeto com o qual trabalha. Não devemos partir de nenhuma identificação a priori dos objetos, precisamos recuperar como ele é tomado por aqueles no meio dos quais ele "vive”. Como fazê-lo? Um dos principais instrumentos de pesquisa é entender as nomenclaturas, seus sentidos, o sistema geral dentro do qual estão inseridas e o papel social de seus enunciadores num determinado lugar e tempo. Dentro dessa perspectiva, na nossa sociedade, é absurdo evitar, dentro de uma discussão sobre arte, ou sobre objetos de modo geral, a discussão sobre estética e sobre o crítico de arte. Ou seja, ao invés de colocar em termos antropológicos um possível e pertinente estudo sobre os críticos de arte ou sobre um objeto que leve em conta o discurso estético, Gell partiu para uma recusa geral, imprecisa, apressada e, talvez, inconseqüente, estabelecendo limites indesejáveis ao pensamento antropológico, convertendo-o em fronteira da realidade, mais do que numa perspectiva de análise.

Dessa imprecisão decorrem outros desdobramentos que contêm os mesmos deslizes: para Gell o estatuto de arte é irrelevante porque a antropologia da

6 Nas palavras do próprio Mauss: “Os fenômenos estéticos formam uma das maiores partes da actividade humana social e não simplesmente individual: uma coisa é bela, um ato é belo, um verso é belo, desde que seja reconhecido como belo pela maior parte das pessoas de gosto. É o que se chama gramática da arte. Todos os fenômenos estéticos são, nalguma medida, fenômenos sociais.”

Horizontes Antropológicos, Porto Alegre, ano 14, n. 29, p. 315-338, jan./jun. 2008 
arte, a fim de se distinguir da sociologia, não pode se restringir ao escopo do que é oficialmente reconhecido como arte, não pode, na verdade, falar em estatuto de objeto de arte, porque esse termo tem indesejáveis exclusivistas conotações. "An object which has been 'enfranchised' as an art object, becomes an art object exclusively, from the standpoint of theory, and can only be discussed in terms of the parameters of art-theory, which what been 'enfranchised' in this way is all about.” (Gell, 1998, p. 12). Algo ser apontado por artístico não o torna objeto de arte apenas do ponto de vista da teoria sobre arte, mas para aqueles que tomam os críticos como referência para o que é ou não arte. Isso não quer dizer, obviamente que há consenso, mas que há um conjunto de especialistas, reconhecidos como tal, que projetam para o conjunto da sociedade uma determinada compreensão do que é artístico e do que não é através da sua atuação como críticos, professores, curadores, etc., e isso é um fenômeno social significativo de ser estudado, como qualquer outro. De resto, é assim que qualquer sociedade ou esfera dentre dela funciona. Não podemos tomar o catolicismo apenas como o que é definido pelos padres e bispos, mas não podemos ignorar a Igreja. Tudo depende, na verdade, de qual é nosso objeto e de como o circunscrevemos. Para aprofundar o exemplo: estudar padres, seu discurso, formação, etc., não é sinônimo de assumir um ponto de vista católico nem significa ignorar que algumas pessoas podem se entender como católicas independentemente da Igreja Católica e até contrariamente a ela.

O cuidado que Gell procurou com esse desprezo pelo reconhecimento estético, entretanto, é extremamente importante e deve ser observado: não podemos transplantar nosso discurso sobre estética a outras culturas e esperar pendurar em seus galhos os frutos que elas produzem. Aqui vemos novamente esse balanço raro entre o brilhante e o primário. A premissa está mais do que correta nas várias formas criativas e inovadoras através das quais Gell a repõe todo o tempo. No entanto, a aplicação desse princípio, sobretudo no que diz respeito às sociedades ocidentais, é enviesada, pois supõe uma relação mecânica primária entre esferas da sociedade e também uma certa homogeneidade na cultura ocidental que marcaria de forma global diferenças entre culturas. Não há qualquer sinonímia entre atribuir a algo o estatuto de obra de arte e o reconhecimento oficial de algo como obra de arte. A atribuição de artístico pode ser feita, inclusive, contra o que é oficialmente reconhecido como tal. Nesse ponto, concordo inteiramente com Layton quanto ele afirma que Gell se vale de exemplos que comprovam sua própria teoria. Além disso, reconheci- 
mento oficial não equivale a reconhecimento institucional. A arte produzida na academia, por exemplo, pode ser contrária àquilo que o Estado oficialmente reconhece como o que representa a nação. Mas as situações concretas com as quais se depara o antropólogo em campo são mais complexas ainda, como lidar, por exemplo, com grupos de artistas que estão fora do que é reconhecido oficialmente ou pelo discurso estético como arte e que lutam para que suas obras tenham o mesmo tratamento institucional que obras de arte canonizadas, para que sejam incorporados em museus e exposições, para que os critérios dos concursos permitam sua participação, e que, no entanto, o fazem freqüentemente sem ter muita ou nenhuma noção sobre estética ou sobre o funcionamento do Estado? Gell compromete, com isso, mecanismos de circunscrição do objeto mais adequados ao que se quer pesquisar.

Dessa forma, o estatuto de objeto de arte é fundamental, se estamos estudando sociedades que tomam esse estatuto como referência, e esse pode ser um ponto interessante de comparação entre sociedades. Compreendo perfeitamente sua proposta de que a definição antropológica não pode se confundir com a estética, o que estou procurando alertar é que ele deveria deixar mais evidente em que nível de discurso e investigação a recusa é necessária e em que nível a sua presença é imprescindível. A verdade é que não é possível a existência do objeto artístico sem que pelo menos um pequeno grupo o reconheça como tal. Nesse sentido, a aproximação entre o oficial e sociologia não faz jus nem aos princípios da sociologia nem da antropologia. Essas confusões reduzem a complexidade da vida social a dicotomias simples e impróprias. A questão central é a seguinte: não podemos ignorar os mecanismos sociais que fazem com que algo seja aquilo que é, do contrário estaremos naturalizando a vida social dos objetos como se algo intrínseco a eles definisse, para além da ação dos homens, a sua natureza.

Nada do que foi dito até agora contradiz a incorporação da agência do objeto de arte na pesquisa. Esse ponto, aliás, não é novo. Merleau-Ponty (2004, p. 23) já postulava, há pelo menos 50 anos, que

as coisas não são, portanto, simples objetos neutros que contemplaríamos diante de nós; cada uma delas simboliza e evoca para nós uma certa conduta, provoca de nossa parte reações favoráveis ou desfavoráveis, e é por isso que os gostos de um homem, seu caráter, a atitude que assumiu em relação ao mundo e ao ser exterior são lidos nos objetos que ele escolheu par ter à sua volta, nas cores que prefere, nos lugares onde aprecia passear. 
Não é preciso discorrer aqui sobre a importância desse filósofo e toda a hermenêutica para a antropologia, que chega, inclusive, não apenas a propor que as coisas sejam tratadas como pessoas, mas vai até mais longe, denuncia que nossa língua expressa essa compreensão que temos dos objetos de maneira espontânea, e que devemos incorporá-la na análise:

Nossa relação com as coisas não é uma relação distante, cada uma fala ao nosso corpo e à nossa vida, elas são revestidas de características humanas (dóceis, doces, hostis, resistentes) e, inversamente, vivem em nós como tantos emblemas das condutas que amamos ou detestamos. O homem está investido nas coisas, e as coisas estão investidas nele. Para falar como os psicanalistas, as coisas são os complexos. É o que Cézanne queria dizer quando falava de um certo "halo" das coisas que se transmitem pela pintura. (Merleau-Ponty, 2004, p. 24).

A transposição cultural ganha, com esse pensamento, uma dimensão bem mais interessante e responsável. O problema não é apenas entendermos os limites e possibilidades da agência dos objetos ou do conceito de estética, mas todo um conjunto de termos e situações concernentes aos objetos e que precisa ser entendido nas suas relações internas e comparativamente. ${ }^{7}$

Shaeffer (2004, p. 25) observa sobre a circunscrição dos objetos estéticos: "Un trait étrange de cette façon de voir reside en ce qu'elle définit lês faits esthétiques comme une classe d'objects qui s’oppose à la totalitté dês autres classes objectales.” Daí a tentação de delimitar uma classe ontológica própria, ao invés de uma subclasse dos objetos em geral. Objetos estéticos partilhariam uma propriedade estética. É exatamente contra esse tipo de suposição que a antropologia evidencia a agência que institui a arte, decomposta na ação de críticos de arte, revistas, cursos, etc. A suposição de que existe uma verdade sobre os objetos contida neles próprios é o princípio básico do preconceito etnocêntrico, incluindo aí o estético. Decorre dessa verdade contida nas coisas que reconhecer a um objeto enquanto artístico é uma questão de capacidade, que se manifesta através do gosto, o que acaba instituindo um determinado gosto como parâmetro para os outros. A antropologia se empenha justamente

Arjun Appadurai (1990), nesse sentido, seria uma referência importante a uma construção teórica mais ampla sobre objetos, artísticos ou não, em nossa sociedade, talvez mais do que Sally Price.

Horizontes Antropológicos, Porto Alegre, ano 14, n. 29, p. 315-338, jan./jun. 2008 
em mostrar que não se existe um gosto universal ou referência universal para nenhuma conformação social, mas de padrões de cultura (para usar um termo de Mary Douglas). Nesse sentido, é um pouco assustadora a afirmação de Gell, destacada também por Layton (2003, p. 448), de que ele está trabalhando com uma identificação intuitiva dos objetos artísticos: "most of the art objects I shall actually discuss are well-known ones that we have no difficulty in identifyng as 'art'; for instance, the Mona Lisa”. Se tomamos como referência o consagrado, ele tem razão, do contrário, a afirmação é totalmente falsa; poucos têm condições de explicar o porquê de ser a Mona Lisa um quadro tão famoso.

A questão central é saber se podemos trabalhar com uma classe específica, a dos objetos artísticos, sem cair nessa ontologização etnocêntrica do mundo. Se podemos incorporar a agência desses objetos e, ao mesmo tempo, denunciá-los enquanto construtos sociais arbitrários. Em outras palavras, respeitar os termos nativos, isto é, a vida própria dos objetos, e tratá-los também como cuja existência social depende da ação humana. Acho mesmo que não há resposta em tese para esse dilema, como o procurou Gell. Não temos como chegar a termo a partir de arranjos lógicos. Os dois princípios são essenciais à antropologia, ao respeito às diferenças culturais. Não há como resolver essa questão sem colocar ênfase no objeto em si, que é exatamente a opção tomada por ele. Veja-se, nesse sentido, várias das análises que ele faz em seu livro a título de exemplificação das suas propostas, nas quais ele omite praticamente todo o contexto de existência dos objetos, que fica reduzido a um conjunto de relações de agência bastante limitado, porque tipificado, como se fosse a única existente num determinado momento e meio. Antes de seguir, porém, é preciso examinar melhor a resposta de Gell.

A definição sugerida por ele não é institucional, estética ou semiótica, é teórica.

The art object is whatever is inserted into the 'slot' provided for art objects in the system of terms and relations envisaged in the theory (to be outlined later). Nothing is decidable in advance about the nature of this object, because the theory is premised on the idea that the nature of the art object is a function of the socialrelational matrix in which it is embedded. (Gell, 1998, p. 7).

Poucos foram tão diretos em alçar o seu próprio nome ao ápice de uma linha de investigação, em pretender uma agência tão importante num campo de conhecimento. Antropologia é linguagem e a abertura de novos filões depende 
de léxico diferenciado. A teoria que ele apresenta incorpora o objeto de arte da seguinte forma:

I propose that 'art-like situations' can be discriminated as those in which te material 'index' (the visible, physical, 'thing') permits a particular cognitive operation which I identift]y as the abduction of agency. (Gell, 1998, p. 13).

Sua definição de índice vem logo sem seguida: uma entidade da qual se pode fazer uma inferência causal, ou inferência sobre as intenções ou capacidades de outra pessoa (Gell, 1998, p. 13). E por abdução ele entende uma regra empírica criada para tornar previsível o que de outra forma permaneceria misterioso (Gell, 1998, p. 14). A dúvida é saber se essa formulação é suficiente para a delimitação de contextos específicos de pesquisa. ${ }^{8}$ Nas páginas seguintes ele aprofunda a explicação sobre esses termos. Para ele, índice, sendo o visível, pode ser o resultado ou o instrumento da ação social. Agência existe em qualquer situação onde uma intenção é atribuída a uma pessoa ou coisa a qual inicia uma seqüência causal.

Gell diz se basear na teoria semiótica de Charles Sanders Peirce ${ }^{9}$ e adiciona que para esse autor o índice é uma inferência causal de algum tipo ou inferência sobre intenções ou capacidades de uma outra pessoa. O seu exemplo, na página 15, para tornar mais claras as suas idéias e noções, é, segundo ele mesmo, bastante usual: fumaça é um índice de fogo. Se há fumaça, supõese que há fogo. Se o mesmo foi provocado por ação humana, então temos agência. Pierce também se vale do exemplo da fumaça, mas antes explica que um índice é um signo que se diferencia do ícone e do símbolo. O que caracteriza o índice é que ele

${ }^{8}$ Esse é o objetivo de Gell, definido na página 4 desse mesmo livro, introduzido como forma de crítica a Boas, que, segundo ele, não teria logrado esse intento.

9 Robert Layton (2003) adotou uma abordagem ao mesmo tempo mais ampla e mais imprecisa sobre essas definições de Gell. Além de Peirce, ele recobra Saussure, Mounin e Humberto Eco, entre outros autores, a fim de avaliar a importância dessas definições para a antropologia. A minha crítica tem um caráter diferenciado, está ligada à construção do argumento em Gell (conforme coloquei no início do artigo); assim, tomei como ponto de partida a importância que ele mesmo atribui ao autor que cita. 
perderia, de imediato, o caráter que faz dele um signo caso seu objeto fosse eliminado, mas que não perderia aquele caráter, caso não houvesse interpretante. Tal é, por exemplo, um pedaço de argila com um orifício de bala, como signo de um tiro, pois, sem o tiro, não haveria orifício; de qualquer modo, está ali um orifício, haja ou não haja alguém para atribuí-lo a um tiro. Um símbolo é um signo que perderia o caráter que o torna signo se não houvesse interpretante. Tal é qualquer modulação de fala que significa o que significa apenas por se entender que tem aquela significação. (Peirce, [s.d.], p. 131).

Ao introduzir o exemplo da fumaça, Peirce visa, na verdade, não uma explicação genérica (ou usual), mas específica. Ele quer tornar claro o tipo de conexão entre o objeto individual e a memória, que caracteriza o signo índice. Essa conexão não é de similaridade nem de analogia, mas dinâmica. "Se A disser a B 'há um incêndio', B responderá ‘onde ?’. Conseqüentemente, A será forçado a recorrer a um indicador, ainda que esteja se referindo apenas a um local indefinido, no universo real, passado ou futuro" (Peirce, [s.d.], p. 131).

$\mathrm{O}$ exemplo acima evidencia que Gell tem um entendimento um pouco diverso de índice do que aquele empregado pelo autor no qual se inspira. Peirce está preocupado com o tipo de conexão entre memória e objeto individual, não define o índice a partir do físico. Na página seguinte, prevendo esse possível equívoco, ele se adianta: “Considerações acima podem conduzir o leitor a imaginar que os indicadores mantêm referência exclusiva com objetos da experiência e que não seriam úteis no campo da matemática pura que lida, como efetivamente lida, com criações ideais, despreocupada de sua concretude.” (Peirce, [s.d.], p. 132). Um dos desdobramentos dessa compreensão enviesada do que é índice são exemplos de agências pautados no objeto real e nas relações que estabelecemos com eles. Pergunta Gell se iria uma garotinha atirar sua adorada boneca para fora de um bote salva-vidas para poder salvar seu irmão chato de se afogar? Claro que não, ele mesmo responde. E o que é o David de Michelangelo senão uma boneca de adultos, conclui. Para ele, a passagem de bonecas a ídolos mede apenas um passo curto. Por que evitamos uma comparação tão óbvia e nos recusamos e ver algo tão evidente? Responde ele que a comparação avilta não apenas porque não gostamos de nos comparar a crianças, mas de comparar bonecas a ídolos (Gell, 1998, p. 18). O objeto, para Peirce, não é o concreto, mas o indicador, que pode não ser material ou ligado à experiência concreta. A comparação adequada, se quisermos seguir as indicações de Peirce, seria então entre o tipo de conexão existente 
nos elementos presentes na situação que envolve a menina e a boneca e o tipo de conexão entre uma pessoa qualquer e o David, não entre a boneca e David diretamente.

A antropologia tem se orientado por essa segunda ordem de perguntas, quais sejam: a atitude dessa garotinha seria a mesma se ela fosse católica ou protestante? se fosse indiana ou européia? como ela passou a imaginar que a boneca era um ser, uma amiga? quem participa dessa fantasia? há algum tipo de ligação entre como alguém concebe uma boneca e a relação geral com os objetos produzidos numa determinada cultura? que tipo de parentesco ela imagina ter com a boneca? Essa linha de investigação construiu-se em oposição à positivista, com ou sem fundamentação biológica, na investigação de eventos ou fatos sociais. Comparar a atitude de um adulto com a de uma criança nos remete à velha suposição de que a relação entre o universo adulto e o infantil é o do desenvolvimento maior ou menor de faculdades inatas. O que ele está evocando é a natureza humana, a realização de uma tendência natural e universal, espontânea. A existência do artefato "boneca”, a sua semelhança com o ser humano e a relação da criança com ela precisam ser explicadas em primeiro lugar, antes de qualquer passo de análise. O que esse exemplo revela, mais profundamente, é a dificuldade que temos em transpor para a arte, enquanto objeto antropológico, alguns procedimentos que aplicamos a qualquer objeto.

Esse apego de Gell ao objeto tem uma motivação: distanciar-se da idéia de que fazer antropologia da arte é desvendar uma linguagem. Escreve ele: "I believe that iconic representation is base on the actual resemblance in form between depctions and the entities they depict or are believed to depict.” (Gell, 1998, p. 25) Eu vi uma vez um livro sobre gnomos que fundamentava suas verdades no fato de que várias culturas, em várias partes do mundo, haviam descrito os mesmo seres "elementais", tanto em aparência como em hábitos, embora utilizando diferentes nomes e entendendo-os cada um à sua maneira. ${ }^{10}$ Aparentemente, há duas formas de explicar essa verdade sobre os gnomos, ou eles realmente existem e quem não crê neles é cego e precisa liberar mais suas energias sensórias, ou estamos diante de um fenômeno de convenção simbólica. A rigor, a antropologia constituiu-se rejeitando ambas as alternativas. Des-

${ }^{10}$ Trata-se de O Livro Secreto dos Gnomos (Poorvliet; Huygen, 1993). 
de a discussão sobre racionalidade em Evans-Pritichard à eficácia simbólica em Lévi-Strauss, os antropólogos atêm-se a sistemas, procuram provar que a verdade de uma cultura é a própria cultura. Seus elementos isolados, quaisquer que sejam, carecem de fundamento, porque estamos sempre nos referindo a modos de viver.

Essas recusas, a do real e a da convenção, são, é claro, incompatíveis, mas apenas se alocadas no mesmo nível de reflexão. Enquanto princípio de realidade, assumimos as verdades dos grupos que estudamos, mas enquanto princípio de análise, não podemos fazê-lo, precisamos tratá-los como convenções, de outra forma, perdemos completamente a razão antropológica e o objeto de pesquisa desaparece. A imagem de Cristo, por exemplo, foi objeto de acaloradas discussões teológicas. Muitos crêem que, ao ver uma pintura, estão vendo como Jesus realmente aparentava. Pintores entendem seu trabalho, inclusive, como uma revelação. A questão é, podemos fazer uma antropologia que envolva imagens de Jesus sem discutir com base em que e como elas foram produzidas? Sem entender certas convenções? São vários os perigos de assumirmos que esta é realmente a aparência do filho de Deus. A primeira delas é de eventual racismo. Muitos grupos cristãos preconceituosos têm como um dos pilares de sua suposta superioridade racial a suposição de que o povo escolhido é branco, e provam isso através dessas visões. Assim, parte importante da luta contra o preconceito é justamente entendermos que representações são o que são, representações, o que não é sinônimo de falsidade ou de mentira. Embora existam povos sujeitos a contatos menos intensos com grupos culturais distintos, não quer dizer que não haja distinções e lutas por versões, e que, no fundo, não se tenha consciência delas.

Bruno Latour (2002), em Deuses Fe(i)tiches, discorre sobre um traço muito curioso da modernidade ocidental: denunciamos o aspecto material e manufaturado dos objetos religiosos de outras culturas como se isso fosse prova de sua ineficácia religiosa e embuste mágico e, ao mesmo tempo, nos valemos de objetos com funções religiosas semelhantes àqueles que imaginamos desconstruir como ingênuos e produtos de mentes primitivas. Ao indagar aos outros sobre a falácia da semelhança ou origem divina de algo, não aplicamos raciocínio idêntico a nós mesmos. Esse é um exemplo no qual vemos as duas opções sendo mobilizadas ao mesmo tempo: um grupo que defende uma semelhança entre o objeto e a entidade e que desmerece um outro grupo por não enxergar que a semelhança que eles supõem entre o objeto e a entidade sobrenatural é produto de convenção simbólica. O que acredita o pesquisador, nesse 
caso, é pouco relevante. O que importa é a situação concretamente vivida. Não cabe ao antropólogo julgar, cabe a ele analisar interações sociais (e nisso estou de pleno acordo com Gell, embora pense que ele tenha se equivocado quanto ao que compõe a relação).

A recusa de Gell à convenção simbólica segue o ritmo de suas colocações: não se posiciona claramente em parceria ou oposição ao trabalho de grandes antropólogos, assim não sabemos exatamente a quem o autor dirige suas críticas, menos ainda o conteúdo claro das mesmas. É muito mais fácil tecer uma crítica geral à idéia de arte enquanto linguagem do que a uma formulação específica. A sua recusa principal, expressa em vários momentos, é à decifração de um código visual de comunicação de significados. Nem a arte pode ser definida a partir do que está ou não integrado a esse código, nem uma antropologia pode se colocar a tarefa de decifrá-lo ou traduzi-lo. Um dos autores mais importante que utiliza essa analogia é Geertz, porém ele não segue propriamente por nenhum dos caminhos que Gell supõe decorrerem dessa opção. Para Geertz (2000, p. 181): "Para que se possa estudar a arte de forma eficaz, a semiótica terá que ir além do estudo de sinais como meios de comunicação, como um código a ser decifrado, e considerá-los como formas de pensamento, um idioma a ser interpretado"; não uma nova "criptografia”, uma substituição de sinais, mas "uma ciência capaz de determinar o sentido que as coisas têm para a vida ao seu redor".

Se há um ponto bastante ultrapassado na antropologia de Geertz, já criticada em muitos autores, sobretudo os pós-modernos, é a extensão desse código, a permanência de uma concepção da sociedade como um todo coerente e organizado, e isso está presente também na sua formulação sobre a arte: "Poderíamos mesmo argumentar que ritos, mitos e a organização da vida familiar ou da divisão do trabalho são ações que refletem os conceitos desenvolvidos na pintura da mesma forma que a pintura reflete os conceitos subjacentes da vida social” (Geertz, 2000, p. 152). Nesse ponto, a crítica de Gell é pertinente, mas também é velha. A arte não necessariamente reflete nada, pode estabelecer uma relação tensa com outros códigos ou mesmo se opor a eles. O livro de Gell parece mais consistente na medida em que não nos damos conta dessas passagens sutis entre uma crítica e outra que ele tece à antropologia antes dele, entre a associação de elementos que parecem próximos mas que não se equivalem, entre uma idéia de decifração e a de todo.

Efetivamente, Geertz (2000, p. 150) recusa a decifração, e isso está bem claro em todo o seu ensaio, e vai mais longe: para ele a relação entre o os 
“elementos simbólicos [...] que compõem um sistema semiótico que, por razões teóricas, gostaríamos de chamar aqui de estético, têm uma conexão ideacional - e não mecânica - com a sociedade em que se apresentam.” Com isso fica evidente que reflexo, para Geertz, tem uma dupla conotação; por um lado, insinua uma coerência geral entre esferas da vida social, por outro, que qualquer tradução envolvendo arte não é possível em outros termos que não os da própria arte, que a relação entre arte e sociedade deve ser estabelecida através de um certo isolamento da arte enquanto esfera autônoma de investigação. Ou seja, que ela é uma porta de entrada tão legítima, auto-suficiente e reveladora como qualquer outra para a pesquisa antropológica. A arte não se explica pela religião, pela política ou pelo humor geral em um dado momento num determinado grupo. Ela tem vida própria. A relação com outras esferas da vida social, portanto, é um dos primeiros passos de investigação (descontada a continuidade do que ele chama de experiência geral frente à vida, eu concordaria plenamente). É isso que ele sugere quando diferencia a arte, em termos gerais, no Ocidente e no resto do mundo, entre termos artesanais e os usados na linguagem comum. O suposto isolamento da arte no Ocidente é exatamente a forma pela qual ela está ligada ao conjunto da sociedade.

Nesse ponto em especial, Geertz é bem mais audacioso que Gell, e suas proposições tornam a questão da aproximação com a estética, no termos do segundo, primárias. Há duas formas de lidar com a relação entre estética e antropologia, a primeira é na forma de estudo, como objeto da antropologia, da mesma forma que a antropologia pode tomar a si mesma e qualquer área por objeto de estudo; a segunda é dialogando com a bibliografia ligada à estética. Nenhuma das duas opções responde à pergunta sobre ser ou não a estética uma categoria transcultural. Na primeira, o tratamento dado seria, em parte, o equivalente ao dispensado a qualquer grupo social, desde punks e skatistas. ${ }^{11}$

\footnotetext{
${ }^{11}$ Kátia Maria Pereira de Almeida (1997, p. 3) destaca uma linha de aproximação bem mais profunda e elaborada na tradição de Pierre Bourdieu. “De fato, como lembra Miceli, Bourdieu parece ter encontrado a saída para o dilema posto pela dicotomia entre ‘objeto de conhecimento' e ‘objeto real’, ao admitir que os fundamentos sociológicos das distinções e categorias que utiliza derivariam da própria divisão do trabalho presente em uma formação social particular.” Assim, a estética, na medida mesmo em que define seu ramo do conhecimento, revela formações sociais particulares. $\mathrm{O}$ mesmo vale para a antropologia, o que coloca a aproximação entre as duas áreas no patamar conjunto da divisão do conhecimento e suas relações com conformações sociais.
}

Horizontes Antropológicos, Porto Alegre, ano 14, n. 29, p. 315-338, jan./jun. 2008 
Já no segundo, seria preciso encontrar pontes possíveis entre os dois campos de estudo, se é que existem (e eu aposto que sim). Um cuidado deve ser mencionado. A estética não compreende uma opinião fechada ou definida sobre nada, não há consenso sobre seu objeto, menos ainda sobre como tratá-lo. Classificar uma produção como estética requer a identificação do autor ou linha de pensamento a partir da qual falamos e de onde tiramos as referências para tal.

Assim, a frase de Gell (1998, p. 3): "I believe that the desire to see the art of other cultures aesthetically tells us more about our own ideology and its quasi religious veneration of art objects as aesthetic talismans, than it does about other cultures" é um pouco superficial quanto ao uso do temo "estético". ${ }^{12}$ Novamente Gell foi impreciso e misturou grupos sociais distintos numa falha considerável sobre a constituição da nossa sociedade. Por um lado, ele está obviamente certo quanto nos exorta a não tomar parte num processo de avaliação da arte primitiva ou da arte produzida em nossa sociedade; por outro lado, essa função não deve ser confundida com a da estética enquanto ramo da filosofia. Mercado de arte, mundo acadêmico, museus e periódicos voltados para o grande público não compõem exatamente o mesmo grupo. Podem mesmo trabalhar com critérios totalmente díspares. Um artista de sucesso pode não ter nenhum reconhecimento de sua produção por parte da estética, do mesmo modo, uma produção altamente considerada pela estética pode não ter qualquer repercussão ou possibilidade de entendimento pela maioria das pessoas, como, aliás, é comum acontecer. A questão de ser ou não a estética uma categoria transcultural é falsa. É preciso, em primeiro lugar, definir uma referência para estética, em segundo, averiguar se ela é útil à antropologia e aos diálogos que estabelece interna e externamente, com outros campos do conhecimento, grupos ou povos. ${ }^{13}$ Um ponto importante da utilidade é, sem dúvida, a compreensão que gera, com a qual é preciso grande cuidado para não cairmos na velha armadilha do etnocentrismo. Colocada em termos genéricos, para reforçar e concluir, a questão não faz sentido e a possibilidade não deve ser descartada.

\footnotetext{
${ }^{12}$ Sobre estética enquanto categoria transcultural, ver Ingold (1996).

${ }^{13} \mathrm{O}$ que dizer, por exemplo, do amplo debate no qual está inserido um crítico de arte como Hans Belting, que incorpora a antropologia e acusa o pretenso universalismo da história da arte em nome do respeito à diversidade cultural? Ver Belting (2006).
} 
No lugar dessa discussão, Gell reforça como critério distintivo de uma antropologia da arte a abdução da agência, termo sobre o qual ainda falta discorrermos. O sentido dessa palavra, para a filosofia de Peirce, é o de indicar o momento inicial do processo indutivo, no qual uma hipótese é selecionada como possível explicação para um fato empírico. ${ }^{14}$ No dicionário Aurélio aparece a acepção de raciocínio imperfeito porém plausível, ou então de apagogia ou rapto violento. Esse segundo conjunto de definições é semelhante ao encontrado no Webster's New World Dictionary. Não estou convencido de que qualquer dessas alternativas é adequada ao tipo de agência exercida por uma obra de arte. Na página 29, Gell, com base na noção de abdução, monta uma tabela que cruza tipos de agência e de pacientes. As colunas e as linhas contêm os mesmos elementos: artista, índice, protótipo, ${ }^{15}$ recipiente. $\mathrm{O}$ artista, assim, pode estar na condição de agente ou paciente. Se em ambos há duas alternativas, como agente ele é a fonte da arte criativa, como paciente ele é testemunha do ato de criação.

Os processos interativos entre pessoas e entre elas e objetos, de quaisquer tipos, me parecem bem mais complexos do que essa tabela pode conter, como o exemplo anterior, tirado de um livro de Bruno Latour, procurou demonstrar. Fazendo um paralelo com uma proposta consagrada nesse sentido, os tipos de dominação, em Max Weber, auxiliam na medida de sua simplicidade e abrangência, o que faz com que não possam ser confundidos com a realidade. Já em Gell, acontece o inverso. Temos, ao todo, 20 possibilidades de relações envolvendo objetos de arte que parecem querer dar conta de todas as formas de interação possíveis.

Depois de todas as desconfianças de Gell quanto à estética, sua análise da obra de Duchamp é, no mínimo, contraditória. Em primeiro lugar porque ele assume as classificações produzidas pelos críticos ao reforçar os rótulos de realistas, cubistas e futuristas. Tivesse Gell considerado um pouco os autores antes dele saberia, através de Elias, ${ }^{16}$ que não podemos nos render a essas classificações tão rapidamente. Em segundo lugar afirma que Duchamp tor-

\footnotetext{
${ }^{14}$ Ver o dicionário de filosofia de Nicola Abbagnano (2007).

${ }^{15}$ Protótipo é a entidade que se acredita representar (Gell, 1998, p. 26).

${ }^{16}$ Em Sociologia de um Gênio, Norbert Elias (1995) assevera que os acontecimentos sociais realmente vividos não têm como ser explicados ou sequer encaixados nas categorias nas quais dividimos os processos artísticos.
} 
nou-se cubista um pouco tardiamente e o fez em função de seu espírito satírico, mais do que por propensão estética. Parece até que a sátira não é uma possibilidade estética, pelo menos é a concepção de Gell a respeito, o que é bem mais rígido e contrário a boa parte do discurso estético, incluindo o do próprio Duchamp. Por último, a idéia de que esse artista materializou conscientemente noções sobre o fluxo do tempo em Russerl, e que tornou possível e visível a agência do objeto, é pouco consistente. Na verdade, esse fluxo é talvez mais claro ainda para artistas acadêmicos. Não havia, antes do modernismo, o empenho com o rompimento de normas estéticas, a construção do papel do artista enquanto vanguarda desafiadora de tudo que veio antes dele. Qualquer pintura pressupunha o diálogo com outras e a criatividade estava ligada justamente a novas soluções para problemas de composição construídas a partir do exemplo das telas daqueles que eram considerados grandes mestres.

Roy Wagner, em um livro seminal, ensinou que o antropólogo não capta a “cultura” em seus processos de investigação, ele procede a uma construção que é dependente da sua relação com um ou mais informantes. Não quero me aprofundar aqui numa seqüência extensa de citações de críticas à noção de cultura a partir desse texto, ou fazer um balanço do pós-modernismo ou outras tendências que incorporaram essas críticas, mas apenas expressar minha surpresa com uma análise que despreza essas contribuições. O que a moderna antropologia ensina é que nem o antropólogo, nem qualquer pessoa, dialoga com essa entidade máxima, suprapessoal, coerente, articulada, monolítica, chamada cultura. Duchamp, portanto, não estava frente à cultura de seu tempo e interagindo com ela. Do ponto de vista metodológico, a primeira questão a saber é onde ele expunha, como suas obras foram recebidas, por quem, quando, em que circunstâncias, etc. Esse tem sido o caminho tomado na produção contemporânea. ${ }^{17}$ Do contrário, o que se pode evidenciar é que uma pessoa vive em seu tempo, o que pode ser interessante do ponto de vista de entendermos algumas características comuns em determinadas épocas ou meios, mas não diz nada de particular sobre essa ou aquela pessoa ou obra. Não quero

\footnotetext{
${ }^{17}$ Essas perguntas não são exclusivas a quem trabalha com a noção de performance, mas são bastante familiares para quem adota essa linha de investigação. Isso explica, em parte, a sua importância, ao invés de partir de dados gerais, recortes predefinidos do real, categorias já estabelecidas, a atenção à performance orienta o pesquisador para as relações real e imediatamente vividas na extensão que elas mesmas têm segundo algum critério que é, ao mesmo tempo, investigativo e dado de realidade.
}

Horizontes Antropológicos, Porto Alegre, ano 14, n. 29, p. 315-338, jan./jun. 2008 
dizer que as características que Gell aponta nos trabalhos analisados sejam falsas, mas que a história das batalhas não é apenas e essencialmente a dos grandes generais, que a genialidade é menos individual do que normalmente se supõe, ela é uma potencialidade da cultura, e é isso que precisa ser investigado em suas realizações concretas. ${ }^{18}$

Há uma série de pontos no livro de Gell com os quais eu certamente concordo: que a antropologia da arte tem que fazer mais do que decifrar códigos, que não lhe compete avaliar trabalhos artísticos, que devemos incorporar a agência dos objetos em termos mais audazes do que o usual, e penso que é por essas características que o livro ficou famoso. A maneira como ele aproximou a arte de todas essas perspectivas da moderna antropologia é realmente inovadora e deve ser aprofundada. É, no entanto, bastante temerosa a sua imprecisão conceitual, como no caso dos termos que incorporou de Peirce; a ausência de teoria antropológica, deixando grandes falhas na sua análise; a sua indistinção entre níveis de análise e os princípios que os orientam, entre metodologia e teoria; por último, é um pouco assustadora a maneira como ele coloca o foco no objeto, tomando a arte como um dado (vide sua análise de Duchamp criticada acima), quase nos reconduzindo à comparação positivista entre elementos descontextualizados.

O ponto de partida de toda sua teoria é o objeto artístico, qualquer que seja a sua definição. A pergunta inicial de investigação, sugerida por Mauss, ainda é a melhor alternativa: o que faz com que algo seja considerado aquilo que é. Do contrário, estaremos cometendo, como demonstrou Schaeffer (2004), uma perigosa ontologização do objeto. Essa pergunta não é incompatível com a incorporação da agência do objeto, como ele faz parecer. O primeiro trabalho que eu conheço que incorpora os objetos artísticos e sua agência de modo direto é justamente a etnografia de Aby Warburg ([s.d.]) entre os índios hopi, há mais de um século. O objetivo central de Warburg é entender como se constitui a forma simbólica; no entanto, conforme aponta Fritz Saxl ([s.d.], p. 149), ${ }^{19} \mathrm{em}$ nenhum momento Warburg se pergunta de que maneira acontece, para os índios, a fusão entre o raio e a serpente durante o ritual que ficou conhecido como “O ritual da serpente”. Para Warburg, como para os índios, o raio é a serpente,

\footnotetext{
${ }^{18}$ Sobre esse assunto, ver Narayan e Rosaldo (1993).

19 Trata-se de uma edição recente que contém comentários ao texto de Warburg, entre eles o de Saxl.
} 
o que demonstra claramente que pesquisar formas não significa ofensa a outros modos de pensamento.

Sempre é bom lembrar os cuidados premonitórios sugeridos por Cardoso (1986, p. 98) já em 1986:

Porém, esta voga de novas técnicas de investigação e o interesse pelos atores sociais de carne e osso não se fizeram acompanhar de uma crítica teóricometodológica consistente. Respondiam a um mal-estar, a um desencantamento com as generalizações apressadas e os esquemas explicativos muito abstratos. Mas a volta ao concreto se deu pelos mesmos caminhos já trilhados pela ciência positivista.

O que ela denuncia é que quadros teóricos viraram declaração de princípios, mais do que construção de referências analíticas. Gell é muito bom nisso, em declarar princípios com os quais, em boa parte, eu concordaria, mas tenho dúvidas se isso é suficiente para estabelecer as bases de uma antropologia da arte, que não pode prescindir, como destacou Layton (2003, p. 460), de considerar que objetos de arte dependem de serem lidos corretamente para serem efetivos como agentes secundários, o que demanda uma aproximação semiológica.

\section{Referências}

ABBAGNANO, Nicola. Dicionário de filosofia. São Paulo: Martins Fontes, 2007.

ALMEIDA, Kátia Maria Pereira de. Distinção e transcendência: a estética sócio-lógica de Pierre Bourdieu. Mana, v. 3, n. 1, p. 155-168, Rio de Janeiro, abr. 1997.

APPADURAI, Arjun. The social life of things. New York: The Cambridge University Press, 1990.

BAXANDALL, Michaell. O olhar renascente: pintura e experiência social na Itália da Renascença. Rio de Janeiro: Paz e Terra, 1991.

BELTING, Hans. O fim da história da arte: uma revisão dez anos depois. São Paulo: Cosac \& Naify, 2006. 
CARDOSO, Ruth C. L. Aventuras de antropólogos em campo ou como escapar das armadilhas do método. In: CARDOSO, Ruth (Org.). A aventura antropológica: teoria e pesquisa. Rio de Janeiro: Paz e Terra, 1986. p. 95-105.

ELIAS, Norbert. Mozart: Sociologia de um gênio. Rio de Janeiro: Jorge Zahar, 1995.

EUFRÁSIO, Mario A. Estrutura urbana e ecologia humana: a escola sociológica de Chicago (1915-1940). São Paulo: Editora 34, 1999.

GEERTZ, Clifford. Arte como sistema cultural. In: GEERTZ, Clifford. O saber local. Petrópolis: Vozes, 2000. p. 142-181.

GELL, Alfred. Art and agency: an anthropological theory. Oxford: Clarendon, 1998.

INGOLD, Tim. Aesthetics is a cross-cultural category? In: INGOLD, Tim (Org.). Key debates in antropology. London: Routledge, 1996. p. 249-293.

LATOUR, Bruno. Reflexão sobre o culto moderno dos deuses fe(i)tiches. São Paulo: Edusc, 2002.

LAYTON, Robert. Art and agency: a reassesssment. Journal of the Royal Antropological Institute, v. 9, n. 3, p. 447-464, 2003.

MAUSS, Marcel. Manual de etnografia. Lisboa: Don Quixote, 1993.

MERLEAU-PONTY, Maurice. Conversas - 1948. São Paulo: Martins Fontes, 2004.

NARAYAN, Kirin; ROSALDO, Renato. Creativity / Antropology. London: London University Press, 1993.

PEIRCE, Charles Sanders. Semiótica e filosofia. São Paulo: Cultrix, [s.d.]

POORVLIET, Rien; HUYGEN, Wil. O livro secreto dos gnomos. São Paulo: Siciliano, 1993.

SAXL, Fritz. Le voyage de Warburg au Nouveau Mexique. In: WARBURG, Aby. Le rituel du sepent. Paris: Macula, [s.d.]. p 149-162. 
SHAEFFER, Jean-Marie. Objets esthétiquees? L'Homme, n. 170, p. 25-46, 2004.

TORN, Cristina. Making the present, revealing the past: the mutability and continuity of tradition as process. Man: The journal of the Royal Antropological Institute, v. 32, n. 4, p. 696-717, dec. 1988.

WARBURG, Aby. Le rituel du sepent. Paris: Macula, [s.d.].

Recebido em 31/10/2007

Aprovado em 03/03/2008 